\title{
METHODS OF CONTROLLED TRANSACTIONS AND THE BEHAVIOR OF COMPANIES ACCORDING TO THE PUBLIC AND TAX POLICY
}

\author{
Constantinos Challoumis \\ National and Kapodistrian University of Athens, Greece
}

date of paper receipt:

10.04.2018.

Original article date of sending to review:

11.04.2018. date of review receipt:

23.04.2018.

UDK: 336.2:339.94

\section{SUMMARY}

This paper aims to the analysis of the most common methods of controlled transactions, and the interpretation of the arm's length principle under the view of the tax income comparison between countries with high and low tax rates. Moreover, the factors of comparability scrutinized with a mathematical approach which shows how the tax factors interact within the countries' economies in the frame of a global view.

Keywords: controlled transactions, transfer pricing, tax impact factors

\section{INTRODUCTION}

The scope of this paper is to represent the methods of controlled transactions subject to the issue of high and low tax policies. The methodology which used is based on the Q.E. method. Therefore is used a quantification method of quality data, to illustrate the behavior of transactions subject to the form of the tax and public policy. Then, based on theoretical structures we determine the behavior of the economic mathematical model, to extract conclusions about the behavior of this model, using quantification and mathematical tools (Q.E. method).

\section{THE CONCEPT OF THE QUANTIFICATION OF QUALITY DATA ${ }^{1}$}

The concept of this theory is based on a methodology which stands on the determination of mathematic equations subject to conditions which also considered. One more important thing is the determination of the upper and the lower limit of the values of the independent variables. Forasmuch as, the dependent variable represents the behavior of selected model, pending on a generator which produces random values to all the independent variables to configure the interaction between them and their behavior under different conditions. At least the basic study includes two facets which are:

- The analysis of the behavior of the model which stands on the scrutiny of the structural characteristics of each model accordingly allowing with that way the extraction of general

1 See paper: Challoumis, Constantinos, Quantification of Everything (A Methodology for Quantification of Quality Data with Application and to Social and Theoretical Sciences) (November 12, 2017). Available at SSRN: https://ssrn. com/abstract=3136014 or http://dx.doi.org/10.2139/ssrn.3136014 
conclusions about the model which is under examination.

- The frequency analysis behavior scrutinizes the behavior of the dependent variables, but from the view of the number of appearances of a variable than another, estimating basically the impact that one independent variable has with one or more others independent variables.

- The dependent variables are these which are modified for the generator. Thereupon, the generator produces values for the dependent variables. The extracted values of the generator allow the creation of magnitudes, which are the base for comparisons, and for the analysis of mathematical equations. With that way is plausible to quantify quality data, and theoretical terms. Moreover, according to this methodology the created magnitudes allow to proceed furthermore to econometrical analyses. In general is a methodology for quantification of quality data. Thus, using the Quantification of Everything (Q.E.) methodology is plausible to clarify the behavior of any model and to determine its standalone behavior, or its comparatively behavior, between different models. Therefore, this methodology as index permits the study of the following issues:

- Is possible the scrutiny and the examination of theoretical themes, from a quality analysis to quantity analysis.

- The creation of magnitudes can be used for any other analysis using that data as axis for further estimations with different scientific tools, and sciences.

- Consequently, the created magnitudes permit an econometric analysis.

- The units which crated don't have an S.I. (International System of Units) or any other type of unit determination system. But, is plausible to determine new units of measure under following international procedures, or only for the aim of each study.

- These units initially if are not determined are "virtual units". The term "virtual units" means that are used only for the purpose of each study and for comparability analysis.

- This methodology of transformation of quality data into quantity data allows a completely different approach of theoretical studies, as it permits the mathematical determination of terminologies, and the study of them in a different scientific field.

Hence, the Q.E. method follows as index four basic steps. The reason which referred as index is because there could be many modifications, and moreover a lot adaptions pending from the subject of study. For the serve of this scope follow these steps.

\section{THE PROCEDURE OF QUANTIFICATION OF QUALITY DATA}

Initially should be noted that that the mathematic approach is that which creates the range of data, and not the opposite. But, the initial determination of the upper and the lower limit of value is for the clarification of the independent variables, so it is irrelevant from the range of data. Then for this reason is not possible to have from the range of data the mathematical determination. Technically is plausible to make this opposite approach, but is out of the scope of this methodology; by strictly point of view. Ergo, each study of quantification of quality data has as initial point the mathematical determination, which comes from the theoretical approach. for this reason the mathematic equation consists and a hypothesis. This means that after the application of this methodology should be checked the consistent of the theory with the quantitation transformation. Otherwise, should be made the appropriate adjustments to comply the mathematical analysis with the theoretical principles. Thereupon, in a different if the theory is not determined and the basis point is the mathematical point of view the analysis initiates from a different point of view. But, always we have a feedback before and after the application of the Q.E. methodology. The collateral of this procedure is the consistency between the results, and the hypothesis, and this happens through a feedback, which always should be considered after the establishment of a theory using a hypothesis or check of an existing theory. Therefore in this point, we conclude the three basic points that the hypothesis and the mathematical determination need to complete its simplest form for the establishment of 
quality data:

- The first step is about the hypothesis. Hence, at this point is determined what it is under thought, and what is the scope of the analysis that follows. Thus, the mathematical determination is the main point of this step.

- The second step is about the generator, which produces the values for the independent variable. The key element is the upper and the lower limit, which used for the productions of values under randomization. This technique allows the formation, of the variables in a quantity control, which is not directed by the scientist. Thereupon, after a critical number of irritations is plausible to sketch the mathematical equation. Inasmuch as concluded the behavior of the equation. This procedure needs at least on mathematical equation, but an appropriate analysis needs at least two mathematical equations, with a lack of some variables, or more variables to the existing equation to understand how the equation reacts in different forms.

- The third step is very critical, as it is the point where is plausible to determine conclusions, and make a feedback with the first step, and with that way is plausible to proceed or with a confirmation of existing theory, or to submit new thesis.

Consequently the three steps which illustrated above show the general concept of quantification quality data. These three steps are illustrated in the next scheme:

Figure 1 Method of quantification of quality data

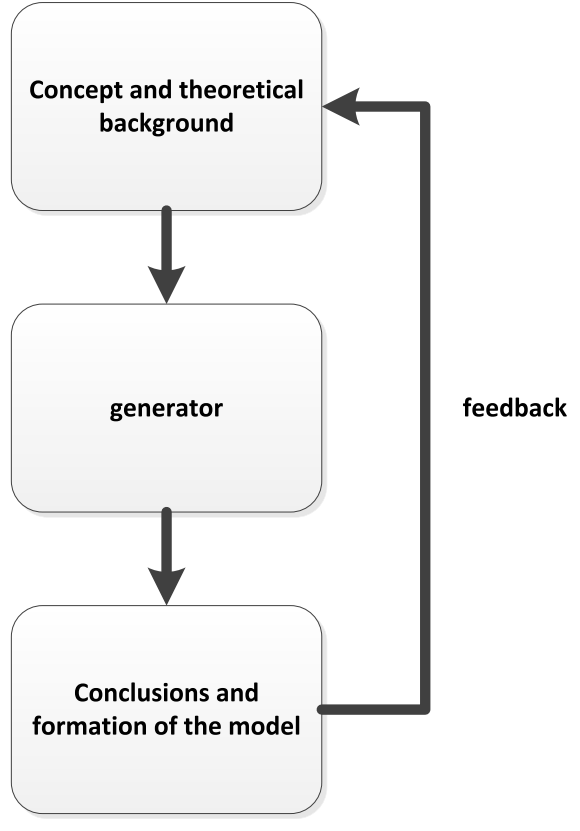

The Q.E. method uses the prior three steps for the formation of the model. The theoretical background or the theory is the source the generator which produced the data and gives shape to the mathematical approach. After the production of data and the formation of the equation is plausible to extract conclusions and/or to proceed to a further mathematical analysis.

\section{THE MOST COMMON METHODS OF CONTROLLED TRANSACTIONS AND THE METHODOLOGY FOR THE PRICES, THE PROFITS, AND THE TAX ANALYSIS}

There is a series of methods that used to identify the controlled transactions from the authorities, but the same procedure is followed by the enterprises which try to aim to the most appropriate method to achieve the best transactions for them. The one method is the CPM method which is the acronym of Comparable Profits Method. Another method is the RPM which is the acronym of 
Resale Price Method. One more method that is used in controlled transactions is the CUP method which is the acronym of the Comparable Uncontrolled Method. And moreover two other methods are the PSM for Profit Split Method and the Cost-plus method.

- In the CPM the authorities compare the data that they have for their own case with the data that are available from the transactions in the market. Therefore is a pricing method that applies intercompany transfers. These comparisons are about the tangible and intangible property. The key element in this method is about the indicators. Therefore, the CPM uses objective measures of profitability. These indicators called profit-level indicators, and are used for the determination of the arm's length price. The uncontrolled companies are the base to extract conclusions about these indicators, because these companies engage in similar business activities under similar circumstances. These indicators apply to the controlled transactions, to find the appropriate arm's length price.[1]

- In the case of RPM the mechanism to control tax avoidance is about the determination of profitability of a distributor. The resale price method clarifies that it is easier for a distributor to determine its gross margin. The price of the resale price method is about the price of the distributor to the consumer. Then, in this situation the transfer price is the price to the customer, less the applicable gross margin which achieved by the distributor. The way to apply the resale price method is based on the adjustments for the differences between controlled and uncontrolled transactions where should be made if the differences between controlled and uncontrolled transactions affect gross margin in the materials. Therefore, these adjustments should be made to the gross profit margin earned from the uncontrolled transactions.

- Moreover, the comparable uncontrolled price (CUP) method estimates the amount charged in a controlled transaction is arm's length. The mechanism in this controlled transaction is about the comparison between the controlled transactions with the comparable uncontrolled transactions. The receipt of comparable data comes from two main sources. The first source is from the analysis of the prospective uncontrolled transactions. The second source is from public exchanges and quotation media.

- In the profit splits method each controlled taxpayer determines its appropriate share of profits in a way that reflects the functions performed, the resources employed, the risks assumed by each company in relevant activities. There is a distinction between profits split method. The first profit split method is about the comparable profit split method, and the second one method is about the residual profit split method. Therefore the comparable profit split method pends on the profit or loss on comparable transactions between two unrelated companies. The conclusion in this situation is that the aim of this method is to tackle operating profits by dividing them among the controlled taxpayers in amounts similar to those arising by the uncontrolled transactions. The second one specific profit split method, which is the residual profit split method is about the combined operation profit and loss from relevant enterprise activity which is allocated between them. It is obtained that the operating income is allocated to each participant to be able to yield a market return to the business activity. The residual profit that belongs to the controlled group's valuable intangible property is distributed between the participants.

- The cost-plus method is a similar method with the resale price method, but the main difference between them is that the RPM uses the profitability of the distributor and the cost-plus method uses the profitability of the manufacturer. The cost-plus method assumes that is more easy for a manufacturer to determine its cost than to use the gross margin of a distributor. On the other hand, the resale price method assumes that it is easier for a distributor to clarify its gross margin than it is for the manufacturer to conclude its cost pricing. Therefore, the cost-plus method of transfer pricing combines the costs that needed to produce the property with the gross profit markup which comes from the costs. The amount that is charged in controlled transactions is compared with the amount of the uncontrolled transactions estimating whether the gross profit markup is arm's length.[2] 
These methods are the base of comparison between controlled and uncontrolled transactions to estimate the tax avoidance of enterprises by their business activity. These are the base for the next theory analysis and the mathematical comparison of tax income between countries.

In addition must be underlined that the methodology which followed is based on the Q.E. method using mathematical analysis and programming tools to establish the conclusions about this economic approach. [3]

\section{TAX INCOME COMPARISON BETWEEN COUNTRIES WITH HIGH AND LOW TAX RATES}

The estimations of all the prior methods for controlled transactions happen through the comparison of prices between the companies that have similar business activities. In this point introduced the equation about the tax income of countries, whose are tax heavens.

$$
s=\sum_{j=1}^{n} s_{j}
$$

The symbol of, shows the impact factor of the tax revenues of the countries which are tax heavens. In addition the countries which lose tax income described by the following equation:

$$
\tilde{s}=+\sum_{i=1}^{m} s_{i}
$$

The symbol of, represents the impact factor of the tax revenues of the countries which are not tax heavens. These countries receive the products that are taxed in different countries losing with that way income. If the companies didn't make tax avoidances then these countries wouldn't lose money by the taxpayers. On that logic the equation (1) and (2) are considered in global economic environment.

The loss of tax income from some countries is more than the profits that make the countries which are tax heavens. This though is based on the principle that this is and the reason why the offshore companies prefer the tax heavens. But, simultaneously this means that the aggregate income in a global view is less, from the case that these tax heavens didn't exist. This doesn't mean that we have negative global tax income [see equation (3)], but that we have losses and this represented in the next equation:

$$
\sigma=s-\tilde{s}<0
$$

The symbol of is the impact factor of balanced tax income. In the previous equation this income is negative because there are tax heavens which cause this loss of global tax income, comparing with the case where the tax heavens weren't exist. This point of view is illustrated by the following equation:

$$
\sigma=0
$$

Therefore, by the previous equation we have the case that uncontrolled transactions represent the market where the transactions are in balance between the countries which are not tax heavens and the countries that could be tax heavens, meaning that these are potential countries for tax avoidance. The interpretation is that in that instance doesn't exist any tax avoidance (equation (4)). A different case is the instance that we have tax heaves, and there are countries which are not tax heavens and countries which are tax heavens. [4] The reason why the equation (3) is negative stands on the view that the global income for (no tax heavens) is more than s (existence of tax heavens). [5][6] 
Figure 2 Tax income factors

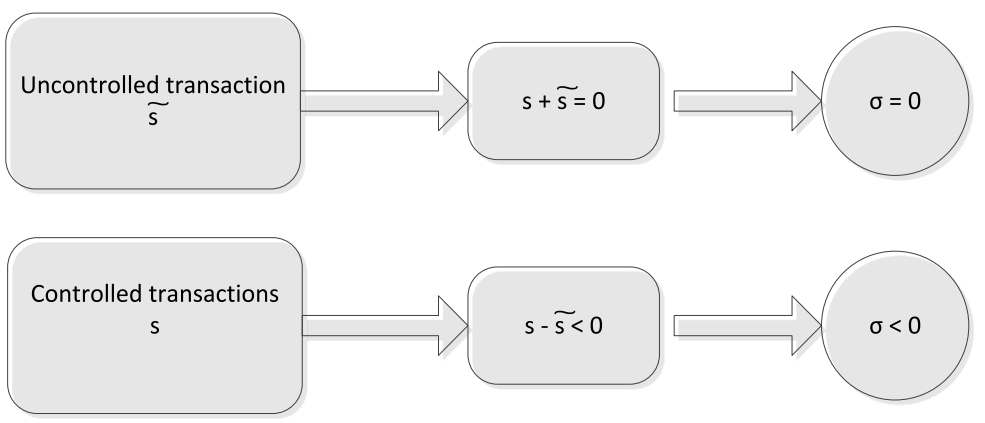

The previous figure for the tax income factor shows the prior analysis for the equations (1), (2), (3), and (4). The equation (4) is an identical view, where globally no tax avoidance through controlled transactions could be achieved by any company.

\section{METHODS WHICH APPLIED IN THE CONTROLLED TRANSACTIONS}

The arm's length principle is an international standard that OECD member countries have agreed to use for taxation. The transfer prices are determined under this standard and are considered as the conditions which made between companies in their commercial relations, and are different from those which would be made between independent companies. This determination according to OECD shows the way how to estimate the profits which are not taxed. The arm's length principle is applied to the prior methods to find the appropriate taxation to the enterprises. The arm's length range is about the acceptance of a control transaction under the arm's length principle. The methodology for the arm's length range is established or by applying the same transfer method to multiple comparable data or from applying different transfer pricing methods. [7]

The enterprises follow procedures to find the most appropriate method, mainly some of the prior referred methods to avoid taxation, or to minimize their tax obligations. Each company chooses the method which prefer, and afterwards the authorities examine the submitted data from the companies, and make comparisons under the OECD standard of the arm's length principle to determine the taxation. The problem for the enterprises and the same time for the authorities is that the available data many times are not so secure and accurate. This means that the data which are referred to extremely similar conditions of uncontrolled business activities is very difficult to be found. Therefore, the enterprises have at least two themes where they can adjust their prices according to arm's length principle:

The enterprises can adjust their prices according to the data that can submit to authorities for the comparison with the uncontrolled business activities of companies.

The enterprises can choose their controlled transaction method.

Therefore, we conclude that the companies which participate in controlled transactions have an extended frame, where they can establish their business activities. Then, the basis for this analysis is the comparison between the controlled and uncontrolled transactions, to identify the most appropriate method to submit their data to the authorities for their taxation. Then, the comparability is the mainstream strategy of the companies which participate in the controlled transactions to achieve the best tax-plan pricing. 


\section{FACTORS OF COMPARABILITY ANALYSIS IN COMBINATION WITH THE IMPACT FACTOR OF BALANCED TAX INCOME}

The comparability that companies use for their controlled transactions can be distinguished in some parts. It is obtained that all factors which affect prices and profits must be considered in the comparability analysis. Therefore, the five factors of comparability analysis are the functional analysis, the contractual terms, the economic conditions, the property or services, and the risk.

The functional analysis aims on the resources employed and anything that is affiliated with these functions, and with the functions performed by the business activities of the companies. According to this transfer pricing approach we have a comparison of functions which performed by a company, and the other connected parties with this company to determine the grade of comparability, between the controlled and the uncontrolled business activities. This happens by comparing the most economically significant activities. This means because companies have not unlimited sources and time, must use the most significant information to extract their conclusions. The main point of functional analysis is to begin with the designing of the product and end with the sales of this product. The factors that are connected with the planning of a product from this as a starting point until the sale of this product are considered as important factors.

The issue about the contractual terms it is important in the controlled transactions, because it is the factor which could affect the transactions between companies, as the terms can affect the prices. Therefore, the companies scrutinize some facets of contractual terms. As index some of them are the payment terms, collateral terms for the business acuities between a buyer and seller, collateral terms between a company and its subsidiary, the form which charged to the tax payer, the volume of purchases, the volume of sales, the warranties, the rights for the intangible property, the duration and the termination of the agreement, and anything relevant with this contractual terms, which could affect the transfer prices between the companies. Then, companies make adjustments to the contractual terms to avoid any unwanted disturbance in their prices. In this point should be referred that there is a separation between written agreements, and non-written agreements. The written agreements are used for the creation of stable and consistent agreements between the companies and their ancillaries. The non-written agreements are very important, because are not so obvious and detectable for the authorities. Then, the result is that the controlled transections possibly are a little bit more insecure, but simultaneously are giving more space to the companies to adjust their transfer prices to the wishing level.[8]

The theme of the economic conditions is one more important factor for the transfer pricing of the business activities. One basic characteristic of this factor is not stable, so the companies should predict and estimate the economic conditions of the countries where they have business activities. As significant economic conditions considered these conditions which can affect the prices and the profits. The impact of economic conditions is important to determine the degree of comparability between the controlled and the uncontrolled transactions. [9] As index some of these economic conditions are the level of similarity between the markets which belong to the same geographical region, the local costs and the cost for distribution of these products, the competition of each market, if the market is a retail or wholesale market, and in general anything that is connected with the significant economic conditions for each case separately.

The factor for the property and services is transfer pricing method where the controlled transactions are considered under the view of the property and the services. These property and services could be considered in a macroeconomic approach as the capital and the labor accordingly. [10] Transfer pricing happens to a company with its subsidiaries for the tangibles, but also the same happens for the intangibles. The intangibles could be a part of the property or a part of the services.

And the risk is one more factor which can have impact to the prices and the profits of the companies which have business activities in controlled transactions. The identification of the risk pends on the entrepreneur, because must decide which risks are important and which of them have significant 
impact to their functionality and to their activities. [11] Therefore, a company which participate in controlled transactions should consider the credit risks, the market risks, the financial risks, the product risks, the liability of the products, the disturbances in the exchange of foreign currency, the fluctuations in the interest rates, the fluctuations in the costs, in the demand, the R\&D activities, and the market risks.[12] The market risks is one of the most significant risks that must an enterprise should consider to its business plan, because affects directly the business activities of the companies. We conclude that independently from the data which used for the scrutiny of the transactions between the companies, in any case the comparability analysis serves the arms' length principle. The companies have the advantage to choose the method which find as best for the determination of their prices and their profits.

Figure 3 Comparability analysis and impact factor of balanced tax income

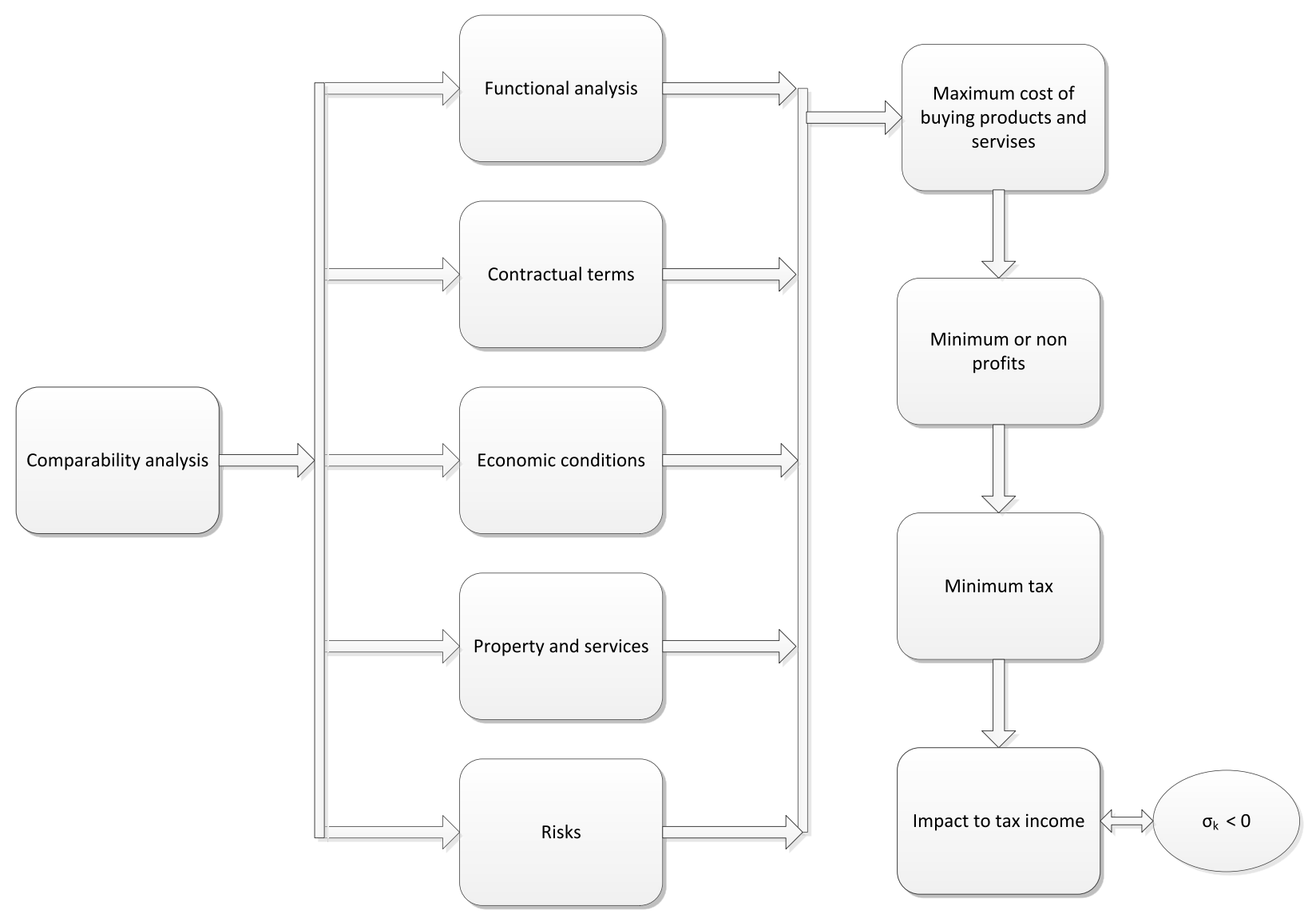

To the previous scheme is concluded that the companies which participate in controlled transactions achieve to allocate their profits, their prices and tax obligations. Enterprises try to maximize their costs in high tax rates environments to achieve less tax in these economic environments. Because, following that procedure these companies present low profits or nonprofits, and then the authorities tax them in limited amounts of money. This figure indicates the case that described in the equation (3).

It is obtained that $\sigma_{k}<0$ represents the limited or the no existence presentation of profits by the companies which participate in controlled transactions. Therefore, for the comparability analysis we have the following equation:

$\sigma_{K}=\sum_{k=1}^{l} \sigma_{k}$, where $k=1, \ldots l$

The symbol of is the impact factor of balanced tax income but for each company separately, and is the aggregate number of companies, which reflect the tax income for the authorities. Subject to the previous figure we have that:

$\sigma_{K}<0$

The equation (6) indicates that we have less tax income, for the reason that there are controlled 
transactions. In a different situation where no tax avoidance could exist, there in that identical situation the equation is this:

$\sigma_{K}=0$

Based on the previous analysis and the arms' length range, companies decide if they would proceed to business activities in the frame of the control transactions. In addition under the perception of the range where the companies should comply, we identify three at least cases which can be used in the comparability analysis:

- The first approach is about the situation where a company has only one method which could apply for its controlled transactions.

- The second approach is about the case where a company has more than one method which could apply for its controlled transactions.

- The third approach is about the situation where a company is not plausible to apply any method for its controlled transactions, and therefore must use special techniques to avoid the difficulties.

The most usual technique is to use different sources of data from the uncontrolled transactions to fix the divergence between the controlled and the uncontrolled transactions.

With the previous analysis of the prices, the profits, the taxation, the impact factors of the tax revenues of the countries which are tax heavens, the countries which are not tax heavens, and the balanced tax income (including and the case of) we can determine the factors that interact with the tax income. Therefore, we have the following equation:

$S=\frac{k+l}{r+c+t}$

Subject to:

$\tilde{k}>k, \tilde{l}>l, r>\tilde{r}, t>\tilde{t}$, and $c>\tilde{c}$

The symbol of defined previously, and the new coefficients are and. The symbol of is about the impact factor of capital, the is the impact factor about the liability of the authorities of the tax system; meaning how much unbalanced it is (making a lot of changes), the $\mathrm{r}$ is about the risk, the $\mathrm{t}$ is about how much trustworthy is the tax system (lack of bureaucracy), and the symbol of $c$ is about the cost of enterprises. The symbols with the " $\sim$ " are accordingly the same thing, but from the view of the uncontrolled transactions. Thus, the numerator is proportional with the income of taxes, as the investments and the stable tax environments, with lack of bureaucracy enhance the tax income. On the other hand the denominator is inverted proportional with the tax income, as the risk, the cost, and the unbalance of taxation cause less tax income. Moreover, for we have that:

$\tilde{s}=\frac{\tilde{k}+\tilde{l}}{\tilde{r}+\tilde{c}+\tilde{t}}$

Considering the equation (9) and the equation (10) we determine the aggregate impact factor of tax revenues, which is symbolized by, and is determined by the following equation:

$\hat{s}=s+\tilde{s}$

In consequence of equations (8), (9), (10), and (11), we continue to a detection of the behavior of the impact factors of tax revenues in the case tax heavens, and in the case of the non-tax heavens. Appling the Q.E. method and choosing the appropriate values for the coefficients we have the following table: 
Table 1 Compiling coefficients

\begin{tabular}{|c|c|}
\hline Factors & Values \\
\hline $\mathrm{k}$ & 0.4 \\
\hline $\mathrm{l}$ & 0.4 \\
\hline $\mathrm{r}$ & 0.6 \\
\hline $\mathrm{c}$ & 0.3 \\
\hline $\mathrm{t}$ & 0.21 \\
\hline $\mathrm{fs}$ & $<0.3$ \\
\hline $\mathrm{f}$ & $>0.3$ \\
\hline
\end{tabular}

The generator of this procedure used the coefficients which appeared on the previous table. This means that generated the prior equations with the values of these coefficients and extracted the next diagrams. Thus, we have that the factors have an upper limit of 1 , and a lower limit 0 , but and are plausible to receive values greater than one as their mathematical structure allow this. After 461 iterations using Q.E. methodology extracted the following diagrams:

(a)(b)

Figure 4: (a) Impact factors of $s$ (series 1) and $\tilde{s}$ (series 2), (b) frequencies $s$ of $\tilde{s}$ and

(a)
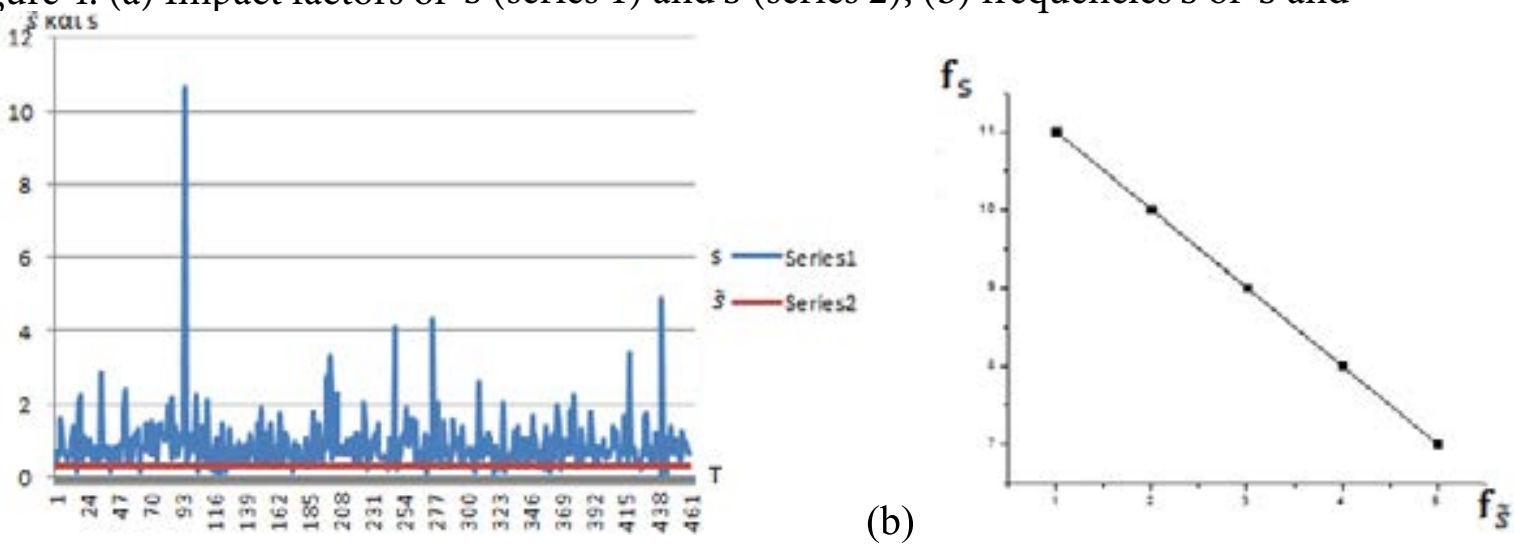

In diagram (a) the $\tilde{s}$ is used as a constant for the comparison with the $s$. The diagram (a) shows that there are some disturbances when the nominator of equation (8) is lower than the denominator. The reason for this is that the tax system hasn't got good characteristics and is not friendly for the enterprises. In diagram (b) we obtain that the frequency of $f_{s}$ is higher than the frequency of $f_{\tilde{s}}$. . Hence, the controlled transactions are more than the uncontrolled transactions. This happens in diagram (b), because as we saw in diagram (a) we have in that examination a bad taxation (high taxation) environment as the denominator of equation (8) is higher than the nominator. Then, the companies prefer to proceed to controlled transactions, to establish more profits, and better allocation to their prices, through their transfer pricing.

\section{CONCLUSIONS}

In this paper we determined the behavior of the controlled and uncontrolled transactions subject to the case of low and high tax economic environments. The controlled transactions are increased in the case that in any economy the taxation is high, and on the other hand the uncontrolled transactions are increased when the taxation is low. Thence, the public and tax policy affect the behavior of the enterprises directly. The theoretical approaches in combination with mathematical and quantification tools allowed the designation of behavior of enterprises subject to the taxation and the public policies. 


\section{REFERENCES}

M. Hallerberg, S. Bassinger Internationalization and changes in tax policy in OECD countries: the importance of domestic veto players Comparative Political Studies, 31 (1998), pp. 321-353

Challoumis, Constantinos, Quantification of Everything (A Methodology for Quantification of Quality Data with Application and to Social and Theoretical Sciences) (November 12, 2017). SSRN: https:// ssrn.com/abstract $=3136014$ or http://dx.doi.org/10.2139/ssrn.3136014

OECD (2017), OECD Transfer Pricing Guidelines for Multinational Enterprises and Tax Administrations 2017, OECD Publishing, Paris.

OECD Taxing Profits in a Global Economy OECD, Paris (1991)

OECD Transfer Pricing Guidelines for Multinational Enterprises and Tax Administrations OECD, Paris (2001)

OECD, 1999. The OECD STAN Database for Industrial Analysis. OECD, Paris.

OECD, 2000. Towards Global Tax Cooperation. Report to the 2000 Ministerial Council Meeting and Recommendations by the Committee on Fiscal Affairs. OECD, Paris.

Feinschreiber R.,2004, Transfer Pricing Methods An Application Guide (John Wiley \& Sons, New Jersey).

D. Wildasin Some rudimentary "duopolity" theory Regional Science and Urban Economics, 21 (1991), pp. 317-331

Ernst and Young, 2000. Transfer Pricing at-a-Glance Guide. Ernst and Young, Rotterdam.

Eden, L., 1995, The microeconomics of transfer pricing, in: A.M. Rugman and L. Eden, eds., Multinationals and transfer pricing (St. Martin's Press, New York).

Eissa, N., \& Hoynes, H. W. (2004). Taxes and the labor market participation of married couples: The earned income tax credit. Journal of Public Economics, 88(9-10), 1931-1958. 